\title{
Preventieve diergeneeskunde bij het konijn
}

\author{
Preventive veterinary medicine in rabbits
}

\author{
K. Hermans \\ Vakgroep Pathobiologie, Farmacologie en Bijzonder Dieren, Faculteit Diergeneeskunde, \\ Universiteit Gent, Salisburylaan 133, B-9820 Merelbeke
}

Katleen.Hermans@UGent.be

AMENVATTING

In dit artikel wordt een overzicht gegeven van belangrijke maatregelen die kunnen worden genomen in de preventie van ziekten bij konijnen. Op kop staat de jaarlijkse vaccinatie tegen myxomatose en "rabbit hemorrhagic disease" (RHD), een handeling die elke dierenarts zou moeten aanraden aan konijneneigenaars. Daarnaast is het verstrekken van correcte voeding ter preventie van onder andere tand- en darmproblemen welbekend. Verder worden een aantal huisvestingstips gegeven die vaak voorkomende gezondheidsproblemen bij konijnen kunnen helpen voorkomen. Obesitas, pododermatitis en urinewegproblemen zijn er enkele van. Minder aangeraden door dierenartsen, doch zeker niet onbelangrijk, is de preventie van uteriene tumoren bij voedsters door middel van electieve chirurgische wegname van ovaria en uterus, bij voorkeur vóór de leeftijd van twee jaar. Een gedegen kennis van de konijnendiergeneeskunde bij de dierenarts en een goede communicatie met konijneneigenaars over hoe ziekte bij hun dieren te voorkomen, kunnen bijdragen tot een lang en gezond leven van gezelschapskonijnen.

\section{ABSTRACT}

In this article, an overview is provided of possible preventive measures that can be taken to safeguard rabbit health. Yearly vaccination against myxomatosis and rabbit hemorrhagic disease for example is key, and should be advised to rabbit owners by every veterinarian. Providing correct feed is also generally accepted as very important in the prevention of both dental and gastrointestinal problems. Some aspects of the housing can help preventing health problems in rabbits, such as obesity, pododermatitis and urinary tract problems. Veterinarians less often advise owners to electively neuter their female rabbits. However, when performed before two years of age, it is an important way of preventing genital tumors such as the frequently occurring uterine adenocarcinoma. A thorough knowledge of veterinarians and a good communication with rabbit owners about the importance of the prevention of disease may aid in obtaining healthier pet rabbits with a better longevity.

\section{INLEIDING}

Konijnen zijn populaire gezelschapsdieren en ook de diergeneeskunde van het konijn heeft in de laatste decennia een hoge vlucht genomen. De literatuur over de geneeskunde van het konijn is zeer uitgebreid en ook op allerlei websites is veel informatie te vinden. Eigenaars van konijnen zijn vaak erg gemotiveerd om met hun dier naar de dierenarts te gaan; de dieren maken net als honden en katten steeds vaker deel uit van het gezin.
Het is voor dierenartsen dan ook belangrijk om goed op de hoogte te zijn van de specificiteiten in verband met konijnengeneeskunde. Vooral op het vlak van preventieve geneeskunde is nog heel wat vooruitgang te boeken. Al te vaak komen konijneneigenaars er immers te laat achter dat een bepaalde aandoening voorkomen had kunnen worden mits een beter management of een preventieve ingreep.

In dit artikel wordt de belangrijkste kennis van preventieve geneeskunde bij het konijn beknopt beschreven. 


\section{AANKOOP VAN NIEUWE DIEREN: BEZINT EER JE BEGINT}

Zoals bij de aankoop van elk huisdier is het nuttig dat potentiële eigenaars zich op voorhand goed informeren over de noden van het dier dat zij in huis willen houden. In tegenstelling tot honden en katten mogen konijnen en andere kleine zoogdieren wel nog te koop worden aangeboden in bijvoorbeeld tuincentra en dierenwinkels, waardoor er allicht vaker impulsaankopen gebeuren en meteen ook voeder en een konijnenhok worden aangekocht. Daar schuilt reeds een gevaar. Eigenaars zijn al te vaak niet goed op de hoogte van de noden van konijnen op het vlak van sociaal gedrag, de inrichting en grootte van de huisvesting en het voeder. Hoewel konijnen sociale dieren zijn, blijkt bijvoorbeeld uit een recente enquête bij Vlaamse en Nederlandse konijneneigenaars dat 30\% van de 1372 respondenten zijn konijn individueel gehuisvest houdt (Winnepenninckx, 2020).

Een aan te bevelen website waar potentiële konijneneigenaars (en ook potentiële eigenaars van andere huisdieren) belangrijke informatie kunnen vinden over onder andere de gedragsnoden maar ook over de kostprijs van het onderhoud van het dier en over preventieve geneeskunde is www.huisdierinfo.be, een website van de Vlaamse Overheid. De Nederlandse variant is te vinden via www.licg.nl.

Bij aankoop van nieuwe dieren kunnen toekomstige eigenaars het beste aangeraden worden om minstens te letten op de afwezigheid van diarree, te controleren of de appositie van de snijtanden in orde is (in kader van aangeboren of verworven gebitsafwijkingen) en uiteraard te letten op de algemene activiteit, alertheid en mobiliteit van de dieren. Verder dienen zij absoluut de vaccinatiestatus van de dieren na te vragen. Het is ook raadzaam de voeding mee te nemen die het konijn op het moment van de aankoop toegediend krijgt; dit om thuis gradueel te kunnen overschakelen naar de voeding die de nieuwe eigenaar wenst te geven. Plotse voederwijziging is namelijk een van de mogelijke oorzaken van dysbacteriose bij konijnen, wat ernstige gevolgen en zelfs mortaliteit met zich kan meebrengen. De stress van een verhuis naar een nieuwe eigenaar kan bovendien ook aanleiding geven tot anorexie en ileus, wat op zijn beurt weer dysbacteriose in de hand kan werken.

\section{MANAGEMENT MET HET OOG OP EEN GOEDE GEZONDHEID}

Tal van managementfactoren spelen een rol in de gezondheid van het dier. Huisvesting en voeding zijn evidente factoren die hier verder besproken zullen worden. Vaccinatie zal apart behandeld worden omdat het van uiterst belang is als preventiemaatregel tegen dodelijke virusziekten; maar ook andere factoren, zoals het al dan niet sociaal huisvesten van dieren, kunnen een impact hebben op de gezondheid. Konijnen zijn immers sociale dieren en de aanwezigheid van een partner in de omgeving zorgt ervoor dat er minder stress en verveling is en meer beweging. Uiteraard is het daarbij belangrijk dat de samen gehuisveste individuen bij elkaar passen. Erge agressie met zware verwondingen tot gevolg komt typisch voor tussen intacte mannelijke dieren. Bij het gezamenlijk huisvesten van mannelijke dieren, zelfs wanneer deze uit hetzelfde nest afkomstig zijn, is castratie dan ook een voorwaarde. Ook bij het gezamenlijk huisvesten van voedsters of bij het samen houden van een mannelijk en vrouwelijk dier of bij grotere groepen, is de compatibiliteit tussen de dieren belangrijk. Echter, vooral de grootte van het hok en de aanwezigheid van voldoende voederplaatsen, drinkwaterpunten, schuilplaatsen en vluchtmogelijkheden zijn belangrijke factoren om het succesvol samenleven van de dieren te bewerkstelligen (Saunders, 2014).

\section{Voeding}

In verband met de voeding is het intussen ruim bekend dat hooi of gras de belangrijkste component van de voeding uitmaakt, zowel voor de bevordering van een normale maagdarmmotiliteit als voor de normale slijtage van het continu doorgroeiende gebit. Omdat eigenaars graag een richtlijn meekrijgen wat 'de belangrijkste component' precies betekent, raden meerdere websites aan om konijnen dagelijks een portie hooi te voederen die qua volume overeenkomt met hun eigen grootte. Naast hooi en gras kan een uniforme pellet van goede kwaliteit worden gegeven, die voldoende vezel bevat. Uniforme pellets krijgen de voorkeur boven de zogenaamde muesli-mixen, om diverse redenen samengevat door Harcourt-Brown (2017). Naast hooi en pellets wordt nog groenvoer aangeboden. Qua groenvoer kunnen konijnen het beste van in het begin gewend gemaakt worden aan een ruime variatie aan groenten, waarbij in hoofdzaak vezelrijke groenten worden aangeboden (Varga, 2014a). Een goede calcium/fosfor-verhouding (1,5$2: 1)$ is eveneens van belang. Onvoldoende calcium en andere onevenwichten in de aanvoer van calcium en fosfor kunnen bijdragen tot tandproblemen (Jekl en Redrobe, 2013). Te veel calcium (bijvoorbeeld door de aanwezigheid van een mineralen-liksteen in de kooi) geeft dan weer potentieel aanleiding tot urolithiasis (Varga, 2014b).

\section{Huisvesting}

Wat de huisvesting betreft wordt vastgesteld dat de meeste konijnen kleiner worden gehuisvest dan hetgeen aangeraden wordt op websites zoals www.huisdierinfo.be en www.licg.nl. Dit heeft onder andere te maken met het aanbod van commerciële kooien op de markt. Er zijn qua afmetingen geen wettelijke minimumnormen voor gezelschapskonijnen beschreven. Naast de huisvesting in een kooi dienen konijnen een 
ruime mogelijkheid tot beweging te krijgen. Dat kan door hen vrij te laten rondlopen in huis (onder toezicht), een 'park' te bouwen waarin zij ruimere bewegingsmogelijkheden hebben of hen in de tuin te laten rondlopen. Beweging is belangrijk als verrijking, ter preventie van obesitas maar ook voor een goede ontwikkeling van het skelet (Buijs et al., 2014).

Obese konijnen zijn niet alleen meer gevoelig voor het ontwikkelen van hart- en vaatziekten, zoals dat ook bij andere dieren en de mens het geval is, ze krijgen ook vaker problemen met het niet opeten van hun caecotrofen ('zachte keutels') en kunnen aldus een zogenaamde 'plakpoep' ontwikkelen, wat dan weer aanleiding kan geven tot dermatitis en in de zomer ook myiasis. Een (te) kleine huisvesting, obesitas en bewegingsstoornissen kunnen eveneens aanleiding geven tot urinewegproblemen, door onder andere het opstapelen van blaaszand. Wilde konijnen plassen immers vaak terwijl ze rennen en als deel van het markeren van hun territorium, in tegenstelling tot een vaak solitair 'sedentair' konijn (Varga, 2014b).

Een goede ondergrond in de huisvesting is eveneens van belang: konijnen die holen kunnen graven, kunnen hun nagels afslijten. Op gras/zand zakken de nagels bovendien in de bodem, zodat er minder druk op de hakken komt te staan. Mancinelli et al. (2014) stelden vast dat, afhankelijk van de leeftijd en het geslacht, een hoog percentage van de gezelschapskonijnen een zekere vorm van pododermatitis heeft door ongeschikte of ruwe ondergronden of onvoldoende korte nagels.

\section{VACCINATIE: OOK BIJ KONIJNEN DEEL VAN HUN JAARLIJKSE DIERENARTSENBEZOEK}

Zoals hoger vermeld is jaarlijkse vaccinatie een erg belangrijk onderdeel van de preventieve konijnengeneeskunde. De virussen die myxomatose en "rabbit hemorrhagic disease" (RHD) veroorzaken, zijn immers nog steeds zeer aanwezig in de wildekonijnenpopulatie in België. Transmissie naar gezelschapskonijnen kan gebeuren door direct contact, maar ook voor de konijnen die binnen worden gehuisvest is er wel degelijk gevaar. Myxomatose wordt typisch overgedragen door steekinsecten (muggen) en RHD kan doorgegeven worden via contaminatie van het voer (ook van hooi, dat immers buiten wordt geoogst) en via insecten zoals vliegen (Asgari et al., 1998). In België zijn meerdere vaccins op de markt die beschermen tegen één of beide varianten van RHD (RHD-1 en RHD-2). Daarnaast is één vaccin geregistreerd en ter beschikking voor vaccinatie tegen myxomatose. Dit laatste is een recombinant vaccin dat bescherming biedt tegen zowel myxomatose als RHD-1 en RHD-2 (Vetcompendium, 2021). Waakzaamheid is echter geboden: nadat België en Nederland in 2016 werden opgeschrikt door een algemene verspreiding van RHD-2 en vaccinfabrikanten hun vaccins dienden aan te pas- sen aan deze nieuwe variant (Hermans et al., 2016), werd recent melding gemaakt van alweer een nieuwe RHD-variant in Frankrijk. Op dit ogenblik blijkt deze variant vooral problemen te geven in de Franse vleeskonijnenhouderij. Er werd door één fabrikant reeds een vaccin ontwikkeld dat zou beschermen tegen deze nieuwe variant en dat in Frankrijk een zogenaamde 'tijdelijke toelating' heeft om gebruikt te worden, dit enkel door vleeskonijnenhouders bij wie reeds een uitbraak van de nieuwe variant plaats vond (Boucher S., persoonlijke mededeling). Op het ogenblik van het schrijven van dit artikel is er nog geen wetenschappelijke literatuur beschikbaar die meer informatie over deze variant geeft.

\section{ELECTIEVE CHIRURGIE: WAAROM OVARIO- HYSTERECTOMIE EEN AANRADER IS}

Het is reeds lang bekend dat vrouwelijke konijnen zeer sterk gepredisponeerd zijn voor het ontwikkelen van baarmoedertumoren, voornamelijk uteriene adenocarcinomen. Reeds in 1959 stelde Greene vast dat $4,2 \%$ en $79,1 \%$ van de 849 onderzochte konijnen een baarmoedertumor vertoonde op respectievelijk twee- tot driejarige leeftijd en op vijf- tot zesjarige leeftijd. Hij beschreef eveneens een hogere incidentie bij bepaalde rassen, zoals het hollanderkonijn. Volgens de auteur komen uteriene adenocarcinomen echter bij alle rassen voor en is uiterste waakzaamheid geboden bij het klinisch onderzoek van een intacte geriatrische voedster die voor jaarlijkse vaccinatie of eender welk probleem in de dierenartsenpraktijk wordt aangeboden. Vaak komt dan immers bij buikpalpatie de aanwezigheid van uteriene massa's aan het licht. Eveneens uit de ervaring van de auteur blijkt dat konijnen vandaag de dag langer leven dan ongeveer twintig jaar geleden, allicht door een betere kennis van eigenaars en dierenartsen en door de preventie van problemen die vroeger voor voortijdige uitval zorgden, zoals de reeds vermelde tandproblemen en virusziekten. Vandaar een pleidooi om aan eigenaars vaker preventieve sterilisatie bij konijnen aan te raden; dit is het beste uit te voeren vóór de leeftijd van twee jaar. Indien de eigenaars ervoor kiezen om dit toch niet te doen, bijvoorbeeld om financiële redenen of omdat zij het anesthesierisico willen vermijden, kan bij de jaarlijkse vaccinatie op zijn minst een grondige buikpalpatie worden uitgevoerd, indien gewenst aangevuld met abdominale echografie. Wanneer op dat moment uteriene massa's worden vastgesteld, kan alsnog ovariohysterectomie worden uitgevoerd. Men dient zich wel bewust te zijn van het risico dat op dat ogenblik reeds metastasen, bijvoorbeeld in de longen, aanwezig kunnen zijn.

Regelmatig wordt de vraag gesteld of ovariectomie op jonge leeftijd voldoende is en dus de uterus niet verwijderd hoeft te worden. Ondanks het feit dat werd aangetoond dat de hormonale cyclus allicht een 
rol speelt in het ontstaan van de tumoren (Asakawa et al., 2008), kon Adams (1962) bij een kolonie proefkonijnen geen verschil vaststellen tussen konijnen die een verschillend aantal nesten gehad hadden. Op dit ogenblik is in de literatuur helaas niet meer informatie beschikbaar en wordt door de meeste dierenartsen en specialisten ovariohysterectomie uitgevoerd, meer bepaald zelfs ovariohysterovaginectomie. Aangezien immers caudaal van de (dubbele) cervix wordt afgebonden, wordt ook een deel van de vagina van het konijn mee weggenomen. Dit vormt echter geen risico, aangezien de urethra erg ver naar caudaal in de vagina uitmondt.

Er zijn nog relatief veel dierenartsen die zich niet echt comfortabel voelen bij de anesthesie van een konijn. Er wordt inderdaad een significant hogere uitval beschreven dan bij hond en kat (Brodbelt et al., 2008). Deze studie van Brodbelt et al. (2008), waarnaar vaak wordt verwezen, werd echter uitgevoerd in Britse praktijken waar de ervaring met anesthesie van konijnen op dat ogenblik variabel was. Er bestaat een groot aantal mogelijkheden om het anesthesierisico te beperken. De anesthesie van het konijn maakt geen onderdeel uit van dit artikel, maar uitgebreide informatie kan bijvoorbeeld worden gevonden in een artikel van Van Zeeland en Schoemaker (2014), dat vrij beschikbaar is op het internet. De recente ontwikkeling van een nieuwe, verbeterde versie van het larynxmasker voor konijnen kan mogelijk nog extra bijdragen tot het veiliger maken van de anesthesie (Docsinnovent, 2021). Uiteraard dient het anesthesierisico met de eigenaar te worden besproken en dient de afweging te worden gemaakt tegenover het mogelijk sluipend ontstaan van baarmoedertumoren.

\section{CONCLUSIE}

Er is een taak weggelegd voor elke dierenarts die konijnen over de vloer krijgt, om eigenaars professioneel advies te geven over preventieve geneeskunde voor hun dier. Jaarlijkse vaccinatie aanraden is een belangrijk gegeven. Indien van toepassing kunnen aanpassingen van voeding en huisvesting het risico op ziekte significant verminderen. Bovendien dient sterilisatie ter preventie van baarmoedertumoren bij vrouwelijke dieren op zijn minst grondig besproken te worden.

\section{REFERENTIES}

Adams W.M. Jr. (1962). The natural history of adenocarcinoma of the uterus in the Phipps rabbit colony. Philadelphia, University of Pennsylvania, Thesis submitted for Master of Medical Science Degree.
Asakawa M.G., Goldschmidt M.H., Une Y., Nomura Y. (2008). The immunohistochemical evaluation of estrogen receptor- $\alpha$ and progesterone receptors of normal, hyperplastic, and neoplastic endometrium in 88 pet rabbit. Veterinary Pathology 45, 217-225.

Asgari S., Hardy J.R., Sinclair R.G., Cooke, B.D. (1998). Field evidence for mechanical transmission of rabbit haemorrhagic disease virus (RHDV) by flies (Diptera: Calliphoridae) among wild rabbits in Australia. Virus Research 54(2), 123-132.

Brodbelt D.C., Blissitt K.J., Hammond R.A., Neath P.J., Young L.E., Pfeiffer D.U., Wood J.L.N. (2008). The risk of death: the confidential enquiry into perioperative small animal fatalities. Veterinay Anaesthesia and Analgesia 35, 365-373.

Buijs S., Hermans K., Maertens L., Van Caelenberg A., Tuyttens F. (2014). Effects of semi-group housing and floor type on pododermatitis, spinal deformation and bone quality in rabbit does. Animal 8, 1728-1734.

Docsinnovent, (2021). https://docsinnovent.com/products/ v-gel-rabbit/, laatst geraadpleegd op 22 september 2021

Greene H.S. (1959). Adenocarcinoma of the uterine fundus in the rabbit. Annals of the New York Academy of Sciences 75, 535-542.

Harcourt-Brown F. (2017). Editorial: reflections on rabbit diets. Journal of Small Animal Practice 58, 123-124.

Hermans K., Moeremans I., Verlinden M., Garmyn A. (2016). België ontsnapt niet aan het "rabbit hemorrhagic disease virus-2" (RHDV2) bij konijnen. Vlaams Diergeneeskundig Tijdschrift 85, 309-314.

Jekl V., Redrobe S. (2013). Rabbit dental disease and calcium metabolism - the science behind divided opinions. Journal of Small Animal Practice 54, 481-490.

Mancinelli E., Keeble E., Richardson J., Hedley J. (2014). Husbandry risk factors associated with hock pododermatitis in UK pet rabbits. Veterinary Record 174(17), 429.

Saunders, R. (2014). Husbandry. In: Meredith A. and Lord B. (editors). BSAVA Manual of Rabbit Medicine. British Small Animal Veterinary Association, Gloucester, pp. 13-26.

Van Zeeland, Y., Schoemaker N. (2014). Current anaesthetic considerations and techniques in rabbits. European Journal of Companion Animal Practice 24(4), 31-45.

Varga, M. (2014a). Rabbit basic science. In: Textbook of Rabbit Medicine. Elsevier, Oxford, pp. 3-108.

Varga, M. (2014b). Urogenital diseases. In: Textbook of Rabbit Medicine. Elsevier, Oxford, pp. 405-424.

Vetcompendium, (2021). www.vetcompendium.be, laatst geraadpleegd op 22 september 2021.

Winnepenninckx E. (2020). Effect of housing on the health of pet rabbits. Masterproef Universiteit Gent, Faculteit diergeneeskunde. Online te raadplegen via https://lib. ugent.be/catalog/rug01:002838024

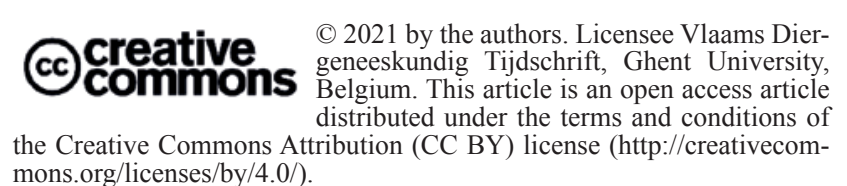
mons.org/licenses/by/4.0/). 